\title{
Comparative Analysis of the Antibacterial Potentials of Some Brands of Toothpaste Commonly Used In Umuahia Abia State
}

\author{
Nwankwo, I. U. And Ihesiulo, S. C. \\ Department Of Microbiology, College Of Natural Sciences Michael Okpara University Of Agriculture Umudike \\ P.M.B 7267 Umuahia Abia State
}

\begin{abstract}
This In-vitro study was carried out to determine the antibacterial efficacy of six different toothpastes against the pathogens isolated from the mouth (Escherichia coli, Staphylococcus aureus and Streptococcus spp) by disc diffusion method. Holdent toothpaste showed maximum zone of inhibition against $S$. aureus, E. coli and Streptococcus spp $(14.00 \pm 1.00,12.33 \pm 0.57$ and $14.00 \pm 1.00$ respectively'. There was no significant difference $(p>0.05)$ between the zones of inhibition for Staphylococcus aureus in both holdent and oral B toothpaste. There was a significant difference ( $p>0.05)$ between the zones of inhibition for Streptococcus species in close up herbal, oral B and hodent toothpaste B. This study demonstrated that triclosan containing toothpaste formulation e.g. holdent is more effective in the control of oral micro flora courpared to non triclosan containing toothpaste e.g. 2080. This work therefore suggest that toothpaste effectively reduced the total bacterial load of the mouth.
\end{abstract}

Keywords: Antibacteral potentials, toothpaste, comparative analysis, Oral bacteria,.

\section{Introduction}

The American Dental Association (ADA) describes toothpaste as a paste or dentifrice used with the aid of a toothpaste to cleanse and maintain the aesthetic and well being of the buccal cavity (tooth). Brushing of teeth using toothpaste is the most commonly practiced form of oral hygiene in most countries (Pannuti et al, 2003). It serves as an abrasive which helps in removeing dental plague and food particles from the teeth, assist in suppressing halitosis and release active ingredients mainly fluoride (Itthagarum and Wei, 1996). The success of any toothpaste, in part, lies on its ability to eliminate pathogenic oral microflora (Degiam, 2010).

In Nigeria, as in other developing countries, a very significant proportion of dental problems are due to microbial infections. Dental problems are of three types, formation of dental plagues, dental caries and periodontal diseases (Manupati, 2011). A wide range of chemicals mainly antimicrobial agents have been added to toothpaste in order to produce a direct inhibitory effect on plague formation (Fine et al, 2006, Pannuti et al, 2003). The addition of antimicrobial agents such as triclosan, fluoride and zinc chloride to toothpaste has been suggested as one possible method to improving the efficacy of mechanical tooth-cleaning procedures (Fine et al, 2006), aiding the periodontal diseases (Ozaki et al, 2006; White et al, 2006).

Bacteria forms an important group of microorganisms seen in both healthy and diseased mouth, this may include the following: Streptococcus spp, Lactobacillus spp, Klebsiella spp Staphylococcus spp, Escherichia coli, Proteus spp etc. (Robert, 2005).

Staphylococus mutans, a bacterium seen in the mouth is known to be one of the major causes of dental plague and may also cause dental caries (Williams and Cummuns, 2003).

The accumulation and development of dental plague is dependent on the result of the interactions between the adhesiveness of plague to the tooth surface and physical sheer forces that helps to remove or dislodge the dental plague (Robert, 2005). Toothpaste and brushes are among the physical forces that remove plague. Active agents such as surfactants, antibacterial agents, baking soda, peroxide, metal sacks herbal and natural extracts and chloride dioxide (Williams and Cummins, 2003) are incorporated into treatment forms. When these substances are added to oral products, they kill microorganisms by disrupting their cell walls and inhibiting their enzymatic activity. They prevent bacterial aggregation, slow multiplication and release endotoxins (Bon-Chacra et al, 2005, Ozaki et al, 2006).

Microorganisms enters the mouth with food, water and air. Contaminated toothbrushes can also be a source for oral bacteria growth. Toothbrushes which are used regularly become contaminated with microorganisms that colonize the teeth and the oral cavity. Under the usual conditions of storage, a toothbrush can therefore serve as a vector for the re-introduction of potential pathogens into the oral cavity, and also for the introduction of other microbial species originating from the bathroom environment (Otoikhian and Okoror, 2012).

Many different products are currently marketed that promise to provide consumers with fresh breath, Dentrifrices need to contain various antimicrobial agents in order to reduce, control and prevent different kinds of dental diseases. Many dentrifices claim to have antimircrobial properties but very little research has been 
conducted to investigate those claims. Based on these facts, the present study aimed at investigating the antibacterial efficacy of different toothpaste against some bacterial isolates from the mouth.

\section{Materials and Methods}

Collection of Specimen: Early morning mouth wash with water were collected from volunteers, which were mainly Students of Michael Okpara University of agriculture, Umudike. Subjects were each given sterile bottle and were instructed not to swallow their saliva as soon as they wake up in the morning.

Isolation Method: Using a streak plate method (Collee et al, 1996), the collected specimen was aseptically streaked on the surface of sterile solid agar (Macconkey agar, Eosin Mehylene Blue and Nutrient agar) with the aid of sterile wire loop. The culture plates were incubated at the temperature of $37^{\circ} \mathrm{C}$ for $24 \mathrm{~h}$ to $48 \mathrm{~h}$.

\section{Characterization and Identification of Bacteria Isolates:}

The isolates were characterized and identified following standard microbiological techniques such as gram staining catalase test, coagulase test, oxidase test, indole test, urease test and sugar fermentation test

Antibacterial Assay: All tooth pastes samples were diluted in sterile water. The antibacterial activity of different concentrations $500 \mathrm{mg} / \mathrm{ml}, 250 \mathrm{mg} / \mathrm{ml}$ and $62.5 \mathrm{mg} / \mathrm{ml}$, of the toothpaste was determined by agar disc diffusion method. In this method, Mueller-Hinton agar plates were seeded with $0.5 \mathrm{ml}$ of $24 \mathrm{~h}$ broth cultures of each isolate, the plates were allowed to dry for $1 \mathrm{~h}$. A sterile forceps was used to place the paper disc impregnated with $0.2 \mathrm{ml}$ of the respective toothpaste, on the surface of the agar. Paper disc impregnated with sterile distilled water was used as negative control.

Plates were incubated at $37^{\circ} \mathrm{C}$ for $24 \mathrm{~h}$. The antibacterial activity was evaluated by measuring the diameher zone of inhibition in millimeter.

The various concentrations mentioned above were used to determine the minimum inhibitory concentration using Mueller- Hinton broth. $9 \mathrm{ml}$ of a sterile Mueller-Hinton broth was dispensed into each tube, then $1 \mathrm{ml}$ of each of the mixed in a test tube. $0.1 \mathrm{ml}$ of inoculums was added to each test tube. The tubes were incubated aerobically at $37^{\circ} \mathrm{C}$ for $24 \mathrm{~h}$. A broad spectrum antibiotic (Gentamycin) was used as positive control. The lowest concentration of the toothpaste that produced no visible growth when compared with the negative control was regarded as the MIC (Kadar, 2005).

\section{Some Commonly Used Toothpaste and their Compositions Toothpaste Ingredients as listed in Packages}

Macleans Sodium fluoride. Aqua, Hydrated Silica, Sorbitol Glycerine.PEG6,Sodium Lauryl Sulphate, Flavour, Xanthan Gum, sodium saccharin, C1-73360,C1-7418.

2080 Sodium monofluorophosphate, sodium carboxymethy Cellulose. sodium lauryl sulphatesodium sacchim, sorbitol. PEG-32, titanium dioxide, flavour, tocopheryl acetate.

Holdent Sodium fluoride, triclosan, sorbitol, silica, water, flavour, cellulose gum. sodium saccharin, food grade red color.

Dabur-Herbal Basil oil, herbal extracts, sodium lauryl sulphate, calcium carbonate. Ginger, eucalyptus and lemonade, sodium silicate glycerin, gum cariagcen, sodium monoflorophosphatc. sodium saccharin.

Close up Herbal Sodium fluoride, sorbitol, aqua, sodium lauryl sulphate, sodium saccharin, PEG-32, aloe vera, barbadensis leaf extract, lemon, $\mathrm{Cl} 73360, \mathrm{Cl} 74260$. $\mathrm{Cl} 772681$.

Oral B Sodium fluoride, sorbitol, aqua, hydrated silica, sodium lauryl sulphate, aroma, cellose gum, triclosan phosphate, sodium saccharin, polyethylene, limonene, Cl 19140, Eugenol, Cl 42090, Carboner

\section{Statistical Analysis}

Statistical analysis was performed using a statistical package, SPSS windows version is by applying mean values using analysis of variance (ANOVA) with post-hoc Duncan method.

\section{Results}

The cultural, morphological and biochemical examination of the growth on the culture plates reveals the isolates to belong to the genera Staphloccus aureus, Streptococcus spp and Eschericharia coli. This is shown in Table 1.

The result of the antibacterial assay of the different toothpaste against staphylococcus arresus is shown in Table 2. As observed from the table, the mean diameter zone of inhibition produced by 2080 ranges from $8.33 \pm 0.58 \mathrm{~mm}$ to $9.33 \pm 0.58 \mathrm{~mm}$, for Darbur Herbal, it ranges from $8.67 \pm 0.58-13.00 \pm 1.00$. That of Close-up herbal ranges from $9.00 \pm 0.00 \mathrm{~mm}$ to $13.33 \pm 0.58$. Macleans ranges from $8.33 \pm 0.58 \mathrm{~mm}$ to $9.33 \pm 0.58 \mathrm{~mm}$, oral B ranges from $6.33 \pm 0.58 \mathrm{~mm}$ to $12.67 \pm 0.58 \mathrm{~mm}$ and Holdent ranges from $6.67 \pm 0.58 \mathrm{~mm}$ to $141.67 \pm 1.00 \mathrm{~mm}$. Oral 
B and Holdent were more effective on the isolate, even at the lowest concentration the exhibited a slight inhibitory effect which was not observed with other toothpaste. Their MIC value was $62.5 \mathrm{mg} / \mathrm{ml} \mathrm{respectively.}$ Table 3 shows the mean diameter zone of inhibition $(\mathrm{mm})$ of the six toothpaste samples on E. coli. None of the toothpaste inhibited the growth of the organism at $62.5 \mathrm{mg} / \mathrm{ml}$ concentration. Macleans exhibited a slight inhibitory effect only at $500 \mathrm{mg} / \mathrm{ml}$ concentration. All the toothpaste except macleans were effective at the concentration of $250-500 \mathrm{mg} / \mathrm{ml}$. The MIC value ranges from $125-500 \mathrm{mg} / \mathrm{ml}$.

As shown in Table 4, all the toothpaste samples inhibited the growth of streptococcus spp. at the concentration of $250 \mathrm{mglml}$ and $500 \mathrm{mglml}$. The highest mean diameter zone of inhibiton was recorded against Holdent, $14.00 \pm 100 \mathrm{~mm}$ and $12.00 \pm 1.00 \mathrm{~mm}$ at $500 \mathrm{mg} / \mathrm{ml}$ and $250 \mathrm{mg} / \mathrm{ml}$ concentration respectively. The MIC value ranges form $125-250 \mathrm{mg} / \mathrm{ml}$.

The result of the zone diameter of inhibiting the standard antibiotic (Gentamycin) is shown in table 5. The highest zone diameter of inhibition was recorded against Streptococcus spp $(21.76 \mathrm{~mm})$ followed by $\mathrm{S}$ aureus $(19.50 \mathrm{~mm})$ while the least was with $\mathrm{E}$ coli $(9.20 \mathrm{~mm})$.

\section{Discussion}

Maintenance of good oral hygiene is the key to prevention of dental diseases (Gamboa et al, 2004). The activities of the oral micro flora are the cause for most oral diseases and mouth odour. The addition of antibacterial agents in the production of toothpaste aids in keeping these oral organisms to a level consistent with oral health.

The present study shows the antibacterial activity of different toothpaste against E coli, S. aureus_and Streptococcus spp as observed from the results, Holdent and oral B emerged as the most effective based on their mean diameter zone of microbial inhibition values. The exceptional ability of these two toothpaste to inhibit the growth of the test organisms even at the least concentration $(62.5 \mathrm{mg} / \mathrm{ml})$ might be due to the presence of Triclosan and Sodium fluoride. Triclosan is an antibacterial and antifungal agent used in the production of toothpaste. It works by inhibiting the enzyme enoyl-acyl carrier protein reductase thereby blocking the lipid biosynthesis (McMurry et al, 1998). Past studies has shown that toothpaste containing Triclosan significantly improves plague control and periodontal health (Gullsolley, 2006).

Among the toothpaste used in this study, fluorinated toothpaste like Maclean and 2080 were not statistically significant. The effectiveness of fluoride toothpaste is concentration dependent (Fejerskov and Kik, 2003). Thus, the low activity of Macleans and 2080 may be due to the low concentration of the ingredient. These toothpaste contain sodium monoflurophosphate and sodium fluoride as active ingredients. Fluorides are widely used in many dental products including toothpaste which aids in many dental products including toothpaste which aids the prevention of dental caries (Marinho et al, 2007).

However, if the bacterial load is too high, it is not possible for it to inhibit the growth completely. This is in agreement with the work done by Davies et al, (2004) where they observed that toothpaste containing triclosan and copolymer provide more effective level on plague control and periodontal health than conventional fluoride toothpaste. The appeared to be equally effective as fluoride toothpaste, Darbur herbal and close up herbal are the herbal products used in this study. This two showed moderate effective as fluoride toothpaste, but not superior to them (Amrutesh et al, 2010). Secondary metabolites such as alkaloik, flauroids and polyphenols present in the herbs used for the production are responsible for the antibacterial activity of these toothpaste (Fatima et al, 2000). The synergistic interaction between the main component of these herbs is seen as a vital part of their effectiveness. However, this synergistic activity needs to be established. This however, is in agreement with a work carried out by Moran et al, (1991) where they observed that herbal toothpaste have rarely been shown to have significantly greater antiplaague activity than other non- herbal toothpaste.

More so, as observed from the results, E coli exhibited moderate resistance potentials to the various toothpaste used than the other test isolate. This however could be as a result of the gram negative nature of $\mathrm{E}$ coli, complexity of its cell wall and possession of antimicrobial resistance plasmids (Kadar, 2005).

\section{Conclusion}

This work revealed that toothpaste containing triclosan was more effective in inhibiting the growth of the bacteria isolates from the oral cavity compared to toothpaste containing sodium fluoride and plant extracts. This suggests that the use of toothpaste made of iriclosan will go a long way to control cases of dental caries and oval diseases. Hence manufacture types of toothpaste for the dental benefit of the general public.

\section{References}

[1]. Amrutesh, S.O, Malini, J.P, Tandur, P.S, and Patki, P.S. (2010): Clinical evaluation of a novel herbal dental cream in plague formation: a double-blind, Randomized, controlled clinical trial. Journal of Experimental Pharmacology 2(1): 105-109.

[2]. Bon-chacra, N.A, Gobi, S.S, Ohara, M.T and Pinto, T.A (2005): Antimicrobial activity of four different dental formulas on cariogenic bacteria evaluated using the linear regression method. Revista Brasilema De Ciencias Farmaceuticas. 42(3): 323-331. 
[3]. Collee, J.A, Fraser, A.G Marmon, B.P. and Simmons, E.D (1996): A Mackie and Mccarteny Practical Medical Microbiology 14 edition Singapore: Longman Singapore. Publishers (Pre) limited.

[4]. Davis, R.M, Ellwood, R.P and Davies, G.M (2004): The effectiveness of a toothpaste inclosan and polyvinyl Methylether Meleic acid Copolymer in improving plague control and guigiva health, a systematic Review. Journal of Clinical Peridontology 31(12):1029-1033.

[5]. Degian, Z.D (2010): An in Vitro Antimicrobial activity of six commercial toothpaste. This-qar Medical Journal (TQMJ):4(4)127133.

[6]. Fatima. S.L, Farooqi, A.H, Kumar, R.E. and Khanuja, S.P. (2000): Antibacterial activity possessed by medicinal plants used in tooth powder: Journal of Medical And Aromatic Plant Science 22(5): 187-189.

[7]. Fejerskou, O.O and Kidd, E.O (2003): Dental caries, the disease and it's clinical management. Ist Edition.Willey-black well publishers, London.

[8]. Fine, K.H., Furgany, B., Markowitz, K, Screeninvasan, P.K, Klimpel K, and D.E Vizio, W (2006): The Antimicrobial effect of a Triclosan Copolymer dentrifrinces on Oral Microorganism in Vitro. J Am Dent. Assoc: 137(10): 1406-1413.

[9]. Gamboa, F.C Estupinan, M.K and Galindo, A.O (2004): Presence of Streptococcus mutans in saliva and its relationship with dental caries. Antimicrobial Susceptibility of the Isolates. Univesitatas Scientiarum Journal 9(2)23-27.

[10]. Gullsolley, J.C (2006). "A meta-analysis of six mouth studies of antiplague and antigingivitis agents. Journal of American Dental Association 137(12):1649-1657.

[11]. Hoikhian, C.S.O, and Okoror, L.O, (2012): Resistance of oral bacterial species to varied toothpaste effects. International Journal of Engineering research and Sciences \& Technology: 1(1): 1-10.

[12]. Itthagarum, A.K and Wei, S.H. (1996): Analysis of fluoride ion concentration and in vitro fluoride utake from different commercial dentrifrices, International dental Journal 46(4): 327-361.

[13]. Kadar, A.A (2005): Prevalence and Antimicrobial Susceptibility of Extended Spectrum Beta Lactamases (ESBL) Producing Escherichia coli and Klebsiella pneumoniae in a general hospital. Clinical Microbiology 25(3): 239-243.

[14]. Manupati, P (2011): Antimicrobial Efficacy of different Toothpaste and Mouthrinses: An in Vitro study Dental Research Journal 8 (2) $85-94$

[15]. Marinho, V.C, Higgins, J.P, Logan, S.V, Sheiham, A.L and Logan, S.G (2007): One Tropical fluoride (toothpaste, mouthrinses, gels or varnishes) versus another for preventing dental caries in children and adolescents. Cochrane Database System Review 8(1):2781.

[16]. Mcmurry, I.M, Oethinger, M.I, and Levy, S.B (1998): Triclosan targets Lipid Synthesis. Journal of Nature 394(6693) 531-532.

[17]. Moran, J.O, Addy, M.H and Newconbe, R.C (1991): Comparism of a herbal toothpaste with a fluoride toothpaste on plague and guigivitis. Clinical Dental Preview 13 (3): 12-15

[18]. Ozakiri,F.M, Pannuti, C.M Imbronito, A.V, Pessotti, W.C, Sara, L.L and Defreitas, N.M. (2006) efficiency of a berbal toothpaste on patient with established gingivitis . A vandonosed controlled trial. Braz Oral Research Journal 20 (2): 314-318.

[19]. Panuti, C.M Mattos, J.P, Ranoya, P.N Jesus, A.M, Lotufo, R.F and Romito, G.A (2003). Clinical effects of a herbal dentrifice on the control of plague and gingivitis. A double blind study Pesqui olotol Brazilian journal 17 (4): 314 -318

[20]. Robert, A.G (2005): Bacteria in the mouth dental update British Journal of Dental Surgery 32(1): $134-142$.

[21]. White, D.J. Kazak. K.M. Gibb, R, Dunavent, J, Klukowska, M and Sagel, P.A (2006): A 24- hour dental plague prevention study with a stannous fluoride dentrifrices containing hexametaphosphate. J Contemp. Dent. Pract. 7(3): 1-11.

[22]. William, M.I and Cummins, D.M. (2003). "The Technology behind close-up total advanced fresh" comprehensive continue education on dentals. British Journal of Dental Surgery 24(5): 4-9.

Table1: Test isolates from Oval Cavity Samples

\begin{tabular}{|l|}
\hline Gram positive \\
\hline Staphyloccus aureus \\
\hline Streptococeus spp \\
\hline Gram negative \\
\hline Escherichia coli \\
\hline
\end{tabular}

Table 2: Mean Diameter Zone of Inhibition $(\mathrm{mm})$ in the Six Toothpaste Samples Against Staphylococcus aureus And Their MIC (mg/ml)

\begin{tabular}{|c|c|c|c|c|c|}
\hline Sample & \multicolumn{4}{|c|}{ Concentration (Mg/Ml) } & \multirow[t]{2}{*}{ MIC } \\
\hline & 500 & 250 & 125 & 62.5 & \\
\hline 2080 & $9.33 \pm 0.58$ & $8.33 \pm 0.58$ & 0.00 & 0.00 & 250 \\
\hline Darbur herbal & $13.00 \pm 1.00$ & $11.33 \pm 0.58$ & $8.67 \pm 0.58$ & 0.00 & 125 \\
\hline Close-up herbal & $13.33 \pm 0.58$ & $12.00 \pm 1.00$ & $9.00 \pm 0.00$ & 0.00 & 125 \\
\hline Macleans & $9.33 \pm 0.58$ & $8.33 \pm 0.58$ & 0.00 & 0.00 & 250 \\
\hline Oral B & $12.67 \pm 0.58$ & $11.00 \pm 1.00$ & $8.67 \pm 0.58$ & $6.33 \pm 0.58$ & 62.5 \\
\hline Holdent & $14.00 \pm 100$ & $11.67 \pm 0.58$ & $9.00 \pm 1.00$ & $6.67 \pm 0.58$ & 62.5 \\
\hline
\end{tabular}

Table 3: Mean diameter zone of inhibition $(\mathrm{mm})$ in the six toothpaste samples against Escherichia coli and their MIC (mg/ml)

\begin{tabular}{l|llll|l}
\hline Sample & \multicolumn{3}{|c|}{ Concentrations $(\mathbf{M g} / \mathbf{M})$} & MIC \\
\hline \multirow{3}{*}{2080} & 500 & 250 & 125 & 62.5 & 250 \\
Darbur herbal & $8.33 \pm 0.58$ & $6.67 \pm 0.58$ & 0.00 & 0.00 & 250 \\
Close-up herbal & $9.33 \pm 0.58$ & $7.67 \pm 0.58$ & 0.00 & 0.00 & 250 \\
Macleans & $9.33 \pm 0.58$ & $7.67 \pm 0.58$ & 0.00 & 0.00 & 250 \\
Oral B & $7.67 \pm 0.58$ & 0.00 & 0.00 & 0.00 & 500 \\
Holdent & $9.50 \pm 1.38$ & $8.33 \pm 0.58$ & $6.33 \pm 0.57$ & 0.00 & 250 \\
& $12.33 \pm 0.57$ & $10.66 \pm 0.57$ & 0.00 & 0.00 & 125 \\
& & & & & \\
\hline
\end{tabular}


Comparative Analysis Of The Antibacterial Potentials Of Some Brands Of Toothpaste .....

Table 4: Mean diameter zone of inhibition $(\mathrm{mm})$ in the six toothpaste sample against Streptococcus spp and their MIC (mg/ml)

\begin{tabular}{l|llll|l}
\hline Sample & \multicolumn{5}{|c|}{ Concentration $(\mathbf{M g} / \mathbf{M})$} \\
\hline \multirow{3}{*}{2080} & $\mathbf{5 0 0}$ & $\mathbf{2 5 0}$ & $\mathbf{1 2 5}$ & $\mathbf{6 2 . 5}$ & \\
\cline { 2 - 5 } Darbur herbal & $7.33 \pm 0.57$ & $6.66 \pm 0.57$ & 0.00 & 0.00 & 250 \\
Close-up herbal & $9.67 \pm 0.57$ & $8.33 \pm 0.57$ & 0.00 & 0.00 & 250 \\
Macleans & $10.33 \pm 0.57$ & $8.67 \pm 0.57$ & $6.66 \pm 0.57$ & 0.00 & 125 \\
Oral B & $9.33 \pm 0.57$ & $7.66 \pm 0.57$ & 0.00 & 0.00 & 250 \\
Holdent & $10.33 \pm 0.57$ & $8.67 \pm 0.57$ & $6.66 \pm 0.57$ & 0.00 & 125 \\
\hline
\end{tabular}

Table 5: Antibacterial diameter zones of inhibition ( $\mathrm{mm}$ ) of Gentamycin

\begin{tabular}{|l|l|l|l|l|l|l|}
\hline Test organism & & & $\begin{array}{l}\text { Zone of } \\
\text { inhibition }(\mathrm{mm})\end{array}$ & & \\
\hline S. aureus & & & & & 19.50 & \\
\hline E. coli & & & & & & 9.20 \\
\hline $\begin{array}{l}\text { Streptococcus } \\
\text { spp }\end{array}$ & & & 21.76 & & \\
\hline
\end{tabular}

